\title{
DETERMINANTS OF EPILEPSY IN CHILDREN AND ADOLESCENTS
}

\section{(6-19YEARS) IN A TERTIARY CARE HOSPITAL IN KANPUR}

\section{NAVNEET KUMAR ${ }^{1}$, TANU MIDHA ${ }^{2} \&$ YASHWANT KUMAR RAO ${ }^{3}$}

${ }^{I}$ Principal and Dean, GSVM Medical College, Kanpur \&Head, Department of Neurology, GSVM Medical College, Kanpur, Uttar Pradesh, India

${ }^{2}$ Associate Professor, Department. of community medicine, Government Medical College, Kannauj, Uttar Pradesh, India

${ }^{3}$ Professor and Head, Department. of pediatrics, GSVM Medical College, Kanpur, Uttar Pradesh, India

Epilepsy is the commonest neurological public health problem in children and adolescents. Very few studies have been conducted on the determinants of epilepsy in India.

Objective

This study was carried out to study the determinants of epilepsy children and adolescents (6-19 years) attending OPD in the Department of Pediatrics, GSVM Medical College, Kanpur.

Methods

This was a cross-sectional study conducted in the outpatient of the Department of Pediatrics, GSVM Medical College, and Kanpur. All children 6 to 19 years of age, attending the OPD from October 2016 to March 2017 meeting the inclusion criteria were included in the study. A pre-tested questionnaire was used to record history, clinical examination, and investigations. Data were analyzed using SPSS version 22.0. Chi-Square test and descriptive statistics were applied. Results

Of the 1232 subjects screened, 59 (4.7\%) were found to be suffering from epilepsy. Around $59.3 \%$ of those with epilepsy were males, which was significantly higher than $48.8 \%$ males among those without epilepsy. Among those with epilepsy, 62.7\% had a positive family history of epilepsy which was significantly higher than among those without epilepsy (34.4\%). Among those with epilepsy, 57.6\% study subjects were born out of consanguineous marriages, which were higher than among those without epilepsy (37.3\%) and this difference was statistically significant. Multiple logistic regression analysis revealed that age, gender, consanguinity and family history of epilepsy were significantly associated with epilepsy.

Conclusion

Epilepsy among children and adolescents (6-19 years) was more common in males as compared to females. Consanguinity and positive family history of epilepsy were associated risk factors.

KEYWORDS: Prevalence, Epilepsy, Determinants \& Family History
}

Received: Nov 21, 2017; Accepted: Dec 11, 2017; Published: Jan 06, 2018; Paper Id.: IJMPSFEB201808 


\section{INTRODUCTION}

Epilepsy is the most common chronic neurological disease of the pediatric age group, characterized by recurrent, unprovoked, paroxysmal seizure activity. ${ }^{1}$ It is now recognized as a global public health problem Cause can range from brain injury, brain tumor, infections of the brain, stroke, and birth defects, which occur through a process called epileptogenesis. Genetic as well as environmental causes such as brain trauma, tumors, stroke, and complications of previous infection cause epilepsy, with one or more factors being the cause. The exact cause is not known in almost $60 \%$ cases. $^{2}$

The mechanism is not clearly known. There is a decrease in the resistance firing of excitatory neurons due to changes in ion channels or when inhibitory neurons fail to perform properly. This leads to the development of seizures from a particular area of the brain, called as "seizure focus". ${ }^{2-5}$ Recent studies have revealed clinically relevant mechanisms of generalized and localized seizures, among which are inherited abnormalities of ion channels, hippocampal sclerosis, cortical malformations, and dysfunction of glial cells. ${ }^{1}$

More research is required on the prevalence of epilepsy and its determinants, to better understand epilepsy and to determine measures for the prevention of its occurrence. Globally, epilepsy is one of the world's most common noncommunicable disease affecting approximately 50 million people. ${ }^{6,7}$ Of these, 40 million are residing in developing countries. In developing nations, epilepsy is more common in older children and young adults, due to differences in the causes of epilepsy in these regions.

There are no recent studies on the risk factors of epilepsy in children and adolescents in. Therefore, this study was done to study the determinants of epilepsy children and adolescents (6-19 years) attending GSVM Medical College, Kanpur.

\section{MATERIAL AND METHODS}

\section{Setting and Design}

This was a cross-sectional study carried out in the outpatient of the Department of Pediatrics, GSVM Medical College, and Kanpur. All children 6 to 19 years of age, attending the OPD from October 2016 to March 2017 meeting the inclusion criteria were included in the study. Ethical clearance was taken from the Institutional Ethical Committee, GSVM Medical College, and Kanpur

\section{Inclusion Criteria}

\section{Children between 6 to 19 years of age}

Children meeting any of the following conditions (Revised ILEA definition of epilepsy ${ }^{8}$ :

- At least two unprovoked (or reflex) seizures occurring greater than 24 hours apart.

- One unprovoked (or reflex) seizure and a probability of further seizures similar to the general recurrence risk (at least $60 \%$ ) after two unprovoked seizures, occurring over the next 10 years. Parents giving written informed consent 


\section{Exclusion Criteria}

Parents not giving consent

\section{METHODOLOGY}

Written informed consent was taken from the parents of children included in the study. Parents were interviewed using a pre-tested questionnaire. The first part of the questionnaire consisted of screening questions to confirm that the child's symptoms met the inclusion criteria. All children classified as suffering from epilepsy based on history were sent for further assessment including clinical examination, EEG ,and other investigations and the diagnosis were confirmed. Thereafter, other details of the study subject to family history (among first degree relatives), age, education and occupation of the parents were recorded.

\section{Statistical Analysis}

Data was compiled and analyzed using SPSS 22.0. Categorical variables were analyzed using percentages and chi -square test. Multiple logistic regression analysis was done to find outdeterminants of epilepsy. A P value less than 0.05 was taken as significant.

\section{RESULTS}

A total of 1232 children and adolescents aged 6 to 19 years were studied. The mean age of the study subjects was $10.6 \pm 2.3$ years. Of the 1232 subjects screened, 59 (4.7\%) were found to be suffering from epilepsy.

Table1 shows the Biosocial characteristics of study subjects. Of the study subjects with epilepsy, 57.6\% were in the age group 6-10 years as compared to $40.4 \%$ in the age group 6 to 10 years among those without epilepsy and this difference was statistically significant. Around 59.3\% of those with epilepsy were males, which were significantly higher than $48.8 \%$ males among those without epilepsy. Religion, the age of the father at childbirth were not significantly associated with epilepsy. Similarly, there was no significant association between epilepsy and education of the mother and father and history of febrile seizures. Age of the mother in childbirth was also significantly associated with epilepsy. Children with epilepsy were born to older mothers. Among those with epilepsy, $62.7 \%$ had a positive family history, which was significantly higher than among those without epilepsy (34.4\%). Among those with epilepsy, 57.6\% study subjects were born out of consanguineous marriages, which were higher than among those without epilepsy (37.3\%) and this difference was statistically significant.

Table 2 shows that multiple logistic regression analysis was used to find out the determinants of epilepsy. It was found that age, gender, consanguinity and family history of epilepsy were significantly associated with epilepsy in the study subjects. For study subjects aged 10 to 19 years, the risk of recurrence decreased by 0.36 times as compared to study subjects with age 10-19 years. Female study subjects were 0.41 times less likely to develop epilepsy as compared to males. Study subjects with a family history of epilepsy were at 3.74 times and those with a history of consanguinity were at 1.15 time's higher risk of developing epilepsy as compared to those without respective history. Age of the mother in childbirth was not associated with recurrence of seizures. 


\section{DISCUSSIONS}

In the present study, the hospital-based prevalence of epilepsy was $4.9 \%$. The community based prevalence was 9.8 per 1000 population in Pakistan and 4.8 per 1000 population among the Parsi community in India. ${ }^{9,10} \mathrm{~A}$ study from Turkey revealed that among 1,625 primary-school students aged 6 to14 years, twenty-two children were diagnosed as epileptic. In males, the prevalence of epilepsy was 4.9/1000, and in females, it was 12.4/1000, representing a total of 8.6/1000.The umulative prevalence in males was 11.0/1000, and 16.1/1000 in females, making a total of 13.5/1000. This difference was due to the fact that hospital -based prevalence has been always higher than that estimated from the community. ${ }^{11}$

In our study, among the study subjects with epilepsy, 57.6\% were in the age group 6-10 years as compared to $40.4 \%$ in the age group 6 to 10 years among those without epilepsy and this difference was statistically significant. Another study found that the median age of onset of seizures was 8 years. ${ }^{12}$ Another study found that the mean age of subjects diagnosed with epilepsy was $11.94 \pm 2.99$ years. ${ }^{13}$

In the present study, around 59.3\% of those with epilepsy were males, which were significantly higher than $48.8 \%$ males among those without epilepsy. Among those with epilepsy, 62.7\% had a positive family history, which was significantly higher than among those without epilepsy (34.4\%). Among those with epilepsy, 57.6\% study subjects were born out of consanguineous marriages, which were higher than among those without epilepsy (37.3\%) and this difference was statistically significant. Other studies have shown a 1.4-fold higher prevalence of epilepsy in males compared to females. ${ }^{10}$ Regarding risk factors for epilepsy, other studies have revealed that about $(68.2 \%)$ had relatives of the same family with a history of epilepsy, and there was a significant association between family history and epilepsy $(\mathrm{p}<0.001) .{ }^{14}$ Prischich et al also observed that there was a significant association between family history and epilepsy. ${ }^{15}$ Another study also showed a positive family history in $40 \%$ of epilepsy cases. ${ }^{14}$

In the present study, age, gender, consanguinity and family history of epilepsy were found to be significantly associated with epilepsy in the study subjects, whereas there was no significant association between epilepsy and education of the mother and father and history of febrile seizures. In another study, however,the risk of epilepsy was 15.1 times higher in those with a history of febrile convulsion. ${ }^{14}$

\section{CONCLUSIONS}

In conclusion, the hospital-based prevalence among children and adolescents (6-19 years) was 4.9\%, higher in males than in females. It was significantly associated with consanguinity and positive family history. Policies and programs must be developed to control the risk factors of the problem. Strengthening of the health system to provide education about the determinants of epilepsy in the community could reduce the prevalence of epilepsy in India.

\section{REFERENCES}

1. Chang BS, Lowenstein DH. "Epilepsy". The New England Journal of Medicine. 2003 349 (13): 1257-66. doi:10.1056/NEJMra022308

2. Longo, Dan L. Chapter 369 Seizures and Epilepsy. Harrison's principles of internal medicine (18th ed.).2012. McGraw-Hill. p. 3258. ISBN 978-0-07-174887-2.

3. Cowan LD. The epidemiology of the epilepsies in children. Ment Retard DevDisabil Res Rev. 2002; 8(3):171-81 
4. Shorvon SD, Farmer PJ. Epilepsy in developing countries: a review of epidemiological, sociocultural and treatment aspects. Epilepsia 1988; 29 (Suppl 1):S36-54.

5. Holms GL, Ben-Ari Y. The neurobiology and consequences of epilepsy in the developing brain. Pediatric Research 2001; 49:320-5.

6. The Global Campaign against Epilepsy. Geneva: World Health Organization; 2000.

7. Newton CR, Garcia HH. Epilepsy in poor regions of the world. Lancet. 2012; 380(9848):1193-201. doi: 10.1016/S01406736(12)61381-6.

8. https://www.ilae.org/guidelines/definition-and-classification/definition-of-epilepsy-2014

9. Aziz H, Ali SM, Frances P, Khan MI, Hasan KZ. Epilepsy in Pakistan. A population based epidemiologic study. Epilepsia. 1994; 35: 950-8. doi: 10.1111/j.1528-1157.1994.tb02539.x.

10. Attia-Romdhane N, Mrabet A, Ben Hamida M. Prevalence of epilepsy in Kelibia, Tunisia. Epilepsia. 1993; 34:1028-32. doi: 10.1111/j.1528-1157.1993.tb02129.x.

11. Huseyinoglu N, Ozben S, Arhan E, Palanci Y, Gunes N. Prevalence and risk factors of epilepsy among school children in eastern Turkey. Pediatr Neurol. 2012; 47(1):13-8. doi: 10.1016/j.pediatrneurol.2012.04.007.

12. Ae-Ngibise KA, Akpalu B, Ngugi A, Akpalu A, Agbokey F, Adjei P, et al. Prevalence and risk factors for Active Convulsive Epilepsy in Kintampo, Ghana. Pan Afr Med J. 2015 ;21: 29. doi: 10.11604/pamj.2015.21.29.6084.

13. Sangrador CO, Palencia Luaces $R$. Study of the prevalence of epilepsy among school children in Valladolid, Spain. Epilepsia. 1991; 32:791-797. doi: 10.1111/j.1528-1157.1991.tb05535.x.

14. Canpolat M, Kumandas S, Poyrazoglu HG, Gumus H, Elmali F, Per H. Prevalence and risk factors of epilepsy among school children in Kayseri City Center, an urban area in Central Anatolia, Turkey. Seizure. 2014; 23(9):708-16. doi: 10.1016/j.seizure.2014.05.012.

15. Prischich F, De Rinaldis $M$, Bruno F, Egeo G, Santori C, Zappaterreno A, et al. High prevalence of epilepsy in a village in the Littoral Province of Cameroon. Epilepsy Res. 2008; 82(2-3):200-10. doi: 10.1016/j.eplepsyres.2008.09.004.

Table 1: Factors Associated with Epilepsyin Study Subjects

\begin{tabular}{|c|c|c|c|c|c|c|c|}
\hline \multirow{2}{*}{\multicolumn{2}{|c|}{ Determinant }} & \multicolumn{2}{|c|}{$\begin{array}{c}\text { Study } \\
\text { Subjects } \\
\text { Without } \\
\text { Epilepsy } \\
(\mathrm{n}=1173)\end{array}$} & \multicolumn{2}{|c|}{$\begin{array}{l}\text { Study Subjects } \\
\text { With Epilepsy } \\
\qquad(n=59)\end{array}$} & \multirow[t]{2}{*}{ Total } & \multirow[t]{2}{*}{ P Value } \\
\hline & & No. & $\%$ & No. & $\%$ & & \\
\hline \multirow{2}{*}{ Age(years) } & $6-10$ & 474 & 40.4 & 34 & 57.6 & 733 & \multirow{2}{*}{$<0.05^{*}$} \\
\hline & $10-19$ & 699 & 59.6 & 25 & 42.4 & 499 & \\
\hline \multirow{2}{*}{ Gender } & Male & 572 & 48.8 & 35 & 59.3 & 607 & \multirow{2}{*}{$<0.05^{*}$} \\
\hline & Female & 601 & 51.2 & 24 & 40.7 & 625 & \\
\hline \multirow{2}{*}{ Religion } & Hindu & 604 & 51.5 & 32 & 54.2 & 636 & \multirow{2}{*}{$>0.05$} \\
\hline & Others & 569 & 48.5 & 27 & 45.8 & 596 & \\
\hline \multirow{3}{*}{$\begin{array}{l}\text { Age of mother at } \\
\text { childbirth }\end{array}$} & $20-39$ & 400 & 34.1 & 17 & 28.8 & 355 & \multirow{3}{*}{$<0.05^{*}$} \\
\hline & $40-59$ & 438 & 37.3 & 22 & 37.3 & 460 & \\
\hline & 60 and above & 335 & 28.6 & 20 & 33.9 & 417 & \\
\hline \multirow{2}{*}{ Education of mother } & Illiterate & 527 & 44.9 & 26 & 44.1 & 553 & \multirow{2}{*}{$>0.05$} \\
\hline & Literate & 646 & 55.1 & 37 & 62.7 & 683 & \\
\hline \multirow{2}{*}{ Mother's occupation } & Working & 526 & 44.8 & 28 & 47.5 & 554 & \multirow{2}{*}{$>0.05$} \\
\hline & Not working & 647 & 55.2 & 31 & 52.5 & 678 & \\
\hline
\end{tabular}




\begin{tabular}{|c|c|c|c|c|c|c|c|}
\hline \multicolumn{8}{|c|}{ Table 1: Contd., } \\
\hline \multirow{3}{*}{$\begin{array}{l}\text { Age of father at } \\
\text { childbirth }\end{array}$} & $20-39$ & 367 & 31.3 & 17 & 28.8 & 384 & \multirow{3}{*}{$>0.05$} \\
\hline & $40-59$ & 405 & 34.5 & 20 & 33.9 & 425 & \\
\hline & 60 and above & 401 & 34.2 & 22 & 37.3 & 423 & \\
\hline \multirow{2}{*}{ Education of father } & Illiterate & 372 & 31.7 & 17 & 28.8 & 389 & \multirow{2}{*}{$>0.05$} \\
\hline & Literate & 801 & 68.3 & 42 & 71.2 & 843 & \\
\hline \multirow{2}{*}{$\begin{array}{l}\text { Family history of } \\
\text { epilepsy }\end{array}$} & Present & 404 & 34.4 & 37 & 62.7 & 441 & \multirow{2}{*}{$<0.05 *$} \\
\hline & Absent & 769 & 65.6 & 22 & 37.3 & 791 & \\
\hline \multirow{2}{*}{ Consanguinity } & Yes & 438 & 37.3 & 34 & 57.6 & 472 & \multirow{2}{*}{$<0.05 *$} \\
\hline & $\mathrm{No}$ & 735 & 62.7 & 25 & 42.4 & 760 & \\
\hline \multirow{2}{*}{$\begin{array}{l}\text { History of febrile } \\
\text { seizures }\end{array}$} & Yes & 527 & 44.9 & 28 & 47.5 & 555 & \multirow{2}{*}{$>0.05$} \\
\hline & $\mathrm{No}$ & 646 & 55.1 & 31 & 52.5 & 677 & \\
\hline
\end{tabular}

$* \mathrm{P}$ value $<0.05$ is significant

Table 2: Multiple Logistic Regression Analysis of Factors Associated with Recurrence of Febrile Seizures in Study Subjects

\begin{tabular}{|l|l|l|l|l|}
\hline \multicolumn{1}{|c|}{ Factor } & OR & $\begin{array}{c}\text { 95\% CI } \\
\text { Lower } \\
\text { Limit }\end{array}$ & $\begin{array}{c}\text { 95\% CI } \\
\text { Upper } \\
\text { Limit }\end{array}$ & P Value \\
\hline Gender (Ref=Male) & 0.36 & 0.17 & 0.78 & $0.008^{*}$ \\
\hline Age (Ref=6-10years) & 0.41 & 0.19 & 0.96 & $0.039^{*}$ \\
\hline $\begin{array}{l}\text { Age of mother at } \\
\text { childbirth(1=20- } \\
\text { 39yrs,2=40-59yrs,3=60 } \\
\text { and above yrs) }\end{array}$ & 1.36 & 0.17 & 2.78 & 0.658 \\
\hline $\begin{array}{l}\text { Family history of } \\
\text { epilepsy (Ref=Absent) }\end{array}$ & 3.74 & 2.29 & 6.12 & $<0.001^{*}$ \\
\hline $\begin{array}{l}\text { Consanguinity } \\
\text { (Ref=Absent) }\end{array}$ & 1.31 & 1.15 & 6.21 & $0.003^{*}$ \\
\hline
\end{tabular}

$* \mathrm{P}$ value $<0.05$ is significant

Reference category for dependent variable is subjects without epilepsy 